\title{
Systematic Division of Coalbed Methane-Enriched Units
}

\author{
Zhang Qinghua $^{1,2,3}$, Zhao Xusheng ${ }^{2,3}$, Wang Qixiang ${ }^{2,3}$ \\ ${ }^{1}$ College of Mining and Safety Engineering, Shandong University of Science and Technology, Qingdao, China \\ ${ }^{2}$ State Key Laboratory of Gas Disaster Monitoring and Emergency Technologies, Chongqing, China \\ ${ }^{3}$ China Coal Technology Engineering Group Chongqing Research Institute, Chongqing, China
}

\section{Email address:}

wqx_cq@foxmail.com (Wang Qixiang)

\section{To cite this article:}

Zhang Qinghua, Zhao Xusheng, Wang Qixiang. Systematic Division of Coalbed Methane-Enriched Units. International Journal of Oil, Gas and Coal Engineering. Vol. 5, No. 1, 2017, pp. 5-12. doi: 10.11648/j.ogce.20170501.12

Received: January 23, 2017; Accepted: February 7, 2017; Published: March 2, 2017

\begin{abstract}
Division of coalbed methane (CBM)-enriched units primarily depends on the analysis of the main controlling factors of $\mathrm{CBM}$ occurrence. The main controlling factors analyzed in this article are sedimentary sequences related to the forming and alteration of CBM, tectonic movement, and burial and hydrocarbon-generation histories. The parameters were measured for independent quantities such as CBM content, gradient, coefficient of extraction difficulty and geological structure complexity. Correlation analysis was conducted between the measured parameters of CBM-bearing systems and the main controlling factors. When the controlling factors are sedimentary sequences and the sedimentary systems tract, the division of CBM-enriched units is based on the coal-forming environment, coal mass distribution and coal characteristics. When the controlling factor is the tectonic matching between the orefield, mining area and mining wells, the division of CBMenriched units is based on tectonic movement. When burial and hydrocarbon-generation histories are the controlling factors, the division of CBM-enriched units is based on metamorphic traits.
\end{abstract}

Keywords: Coalbed Methane, Geological Unit Division, Sedimentary Sequence, Tectonic Movement, Coal Grade

\section{Introduction}

Coalbed methane (CBM) development can convert waste into resources, help optimize the energy structure and reduce environmental pollution. To achieve CBM extraction and utilization, as well as disaster prevention, determination of the target CBM-enriched blocks is a priority. Many studies [2-7] have been devoted to the division of CBMenriched units, including those based on big data thinking [1], multiple superposed CBM-bearing systems [5-6] and stepwise tectonic control [6-8]. The research findings provide valuable information for the evaluation and selection of CBM-enriched units under China's complex geological conditions. However, the early stage of commercial CBM exploitation has just started in China, and there are not many large CBM development blocks. The spatial distribution of the gas-bearing property and permeability shows a strong heterogeneity, leading to a limited scope of geological blocks and uncertain prospects for CBM development. Therefore, it is important to develop a systemic understanding and refined division of CBM- bearing systems in the absence of kinetic connections. The knowledge of sedimentary sequences associated with the forming and alteration of CBM can then be applied to the division of units. These components are necessary for largescale, centralized CBM development, selection of highyield CBM blocks and optimal layout of CBM wells.

Division of CBM-enriched units has evoked widespread attention, and many theoretical investigations have been conducted, such as those based on big data thinking, multiple superposed CBM-bearing systems and stepwise tectonic control, as mentioned above. Division based on big data thinking generally relies on "correlation laws" discovered by the analysis of massive macroscopic data to make predictions. However, China lacks centralized information management of CBM development data. The presence of several CBM-bearing systems over the vertical profile of the stratum sequences is highlighted by the theory of multiple superposed CBM-bearing systems. However, there are very few kinetic connections between these CBM-bearing systems. Stepwise tectonic control theory is concerned with the control that high-grade tectonic stress fields and structural 
features impose on low-grade tectonic stress fields and structural features. High-abundance CBM-enriched regions and belts, along with favorable regions for CBM development that are dominated by squeezing and shearing, can be delineated utilizing the stepwise tectonic control theory. However, the factors of sedimentary sequences as well as burial and hydrocarbon-generation histories have been neglected.

Identifying the CBM-enriched units with homogeneous properties (CBM enrichment and coalbed alterability) is the major task of geological studies of CBM development. Geological units not only differ in the pressure of CBM reservoirs, but also display zoning features of CBM content, gradient, pressure, gushing amount, permeability and geological structure complexity. The law of CBM occurrence, which can be revealed by research and analysis of CBM occurrence, is closely related to sedimentary sequences, tectonic movement and the burial and hydrocarbon-generation histories of the geological bodies. Therefore, the division of CBM-enriched units should be primarily based on the sedimentary sequences of the forming and alteration of CBM, considering tectonic movement in addition to burial and hydrocarbon-generation histories.

\section{Basic Principles}

Division of CBM-enriched units can be based on the law of CBM enrichment. Faults, folds, coal masses and surrounding rocks that have an influence on coal and gas outburst are formed after a long geological history of sedimentary evolution, tectonic movement, and burial and uplift of the geological bodies. The controlling factors for CBM distribution vary from one region to another; some factors control zonation, while others exert a secondary or local influence. The sealing ability of cap rock for CBM reservoirs varies in different sedimentary systems, and systems tracts differ in terms of microscopic structure, gas production capacity, thickness variation, transverse morphology, and top and bottom plates. The main control structures and local structures can be identified by structural analysis, based on which the multi-level refined division of the orefield, mining area and mining wells can be determined. CBM blocks with a large amount of measured data were studied in this paper, and CBM content models for different geological units were built to verify the validity of the division of CBM-enriched units based on burial and hydrocarbon-generation histories and coal grade. Examples and data are presented for further explanation and verification.

\section{Sedimentary Sequences}

The geological units of CBM-bearing systems are transversely divided by the sedimentary environment. Production wells of the coal-bearing Longtan Formation in the Yangtze Plate in China have been analyzed. It was found that $97.90 \%$ of coastal deltaic sedimentary facies are enriched with CBM. Alluvial fan and fluvial sedimentary systems have relatively low sealing ability, and are more commonly found in Fuyuan, Xuanwei, Weining and Leshan. Barrier coasts and fluvial sedimentary systems have a larger sealing ability for CBM and are more commonly found in North Guizhou, Zhina, Liupanshui, Jincheng and Anhe.

The division of sedimentary sequences is essentially a more refined division of the sedimentary environment, controlling the distribution of the sedimentary morphology of coal masses and the lithology of the top and bottom plates. Coal seams formed under different systems tracts also differ in microscopic structure, gas production ability, thickness variation, transverse morphology and top and bottom plates [8]. A study on the sequences of coal seams can greatly inform the reconstruction of the coal seam profile and planar spread. The thickness variation index and trend value of a coal seam can be calculated to reflect the primary thickness of the coal seam. Thick coal seams have mainly developed on top of transgressive systems tracts near the maximum flooding surfaces where the lithology of the top and end plates is compact and the thickness is stable, enabling the preservation of CBM. In contrast, coal seams in the lowstand and highstand systems tracts developed much later and the coal seam thickness varies greatly. Intense CBM enrichment usually occurs in the regions with abrupt changes in coal seam thickness or dip angle. Performing refined sequence stratigraphic analysis and building an isochronous stratigraphic framework can contribute to the understanding of the coal-forming environment and coal mass distribution characteristics and lead to the identification of CBMenriched units.

\section{Tectonic Movement}

\subsection{Identification of Main Control Structures}

Tectonic movement is concerned with the dynamic evolution of geological bodies. Historical tectonic stress has an influence on the current $\mathrm{CBM}$ distribution; the structural morphology that we observe today reflects the process and intensity of the tectonic movement. The influence of the intensity of tectonic movement on CBM enrichment mainly depends on the degree of tectonic coal development, variations in the geometric morphology of the coal seams and the stress state. These factors can be qualitatively or quantitatively analyzed using certain tools. For example, tectonic coal thickness can be quantified by an apparent resistivity curve (DLW) and a Gamma curve (HGG). Variations in the geometric morphology of the coal seams can be quantified by residuals, and stress state by the tectonic line curvature method [7]. Different CBM-enriched units vary in CBM content, $\mathrm{CBM}$ content gradient, coefficient of extraction difficulty and local structure. Stepwise tectonic control is the main theory used for the division of CBMenriched units in orefields, mining areas and mining wells. CBM content models are built for different CBM-enriched units and then verified by the measured CBM parameters, 
which provides reference for the selection of CBM blocks.

\subsection{Division of CBM-Enriched Units in the Xusu Arc Structure}

The Xusu arc structure is one of the regions where CBM enrichment is mainly influenced by tectonic movement, which controls the structural evolution, stress field distribution, structural framework and division of CBMenriched units. The Xusu arc structure [16] (Figure 1) is composed of several arc structures that have been bent three times, including the Suxian mining area, Linhuan mining area, Suisu mining area and Woyang mining area. The CBM resources are abundant in this region. Xusu arc structure underwent multiple phases of horizontal tectonic movement in history. By geometric morphology, it is divided into an outer arc, middle arc and inner arc. The outer arc belongs to the front of the nappe structure and aligns with the Dawuji synclinorium -Tongting anticline. The margin of the arc top has developed extensional fractures. The tectonic line curvature of the inner arc is larger than that of the outer arc, and the inner arc aligns with the Zhihe synclinorium -Sudong syncline. The inner arc features stress concentration, severe squeezing and many thrust faults. The arc top is the site of the strongest stress concentration, and the stress is weakened towards the arc center and the two sides. Structural zoning corresponds well with CBM enrichment. CBM content is generally higher in the middle of the arc than on the two wings, and it is higher in the inner arc than in the outer arc. The Suxian mining area has the highest CBM content, which ranges from 12 to $15 \mathrm{~m}^{3} / \mathrm{t}$, and that of the Linhuan mining area $\left(8-12 \mathrm{~m}^{3} / \mathrm{t}\right)$ is larger than that of the Suixiao mining area $\left(8-10 \mathrm{~m}^{3} / \mathrm{t}\right)$. The lowest CBM content is found in the Wuyang mining area, below $8 \mathrm{~m}^{3} / \mathrm{t}$ (Figure 3 ). CBM content of single wells also shows the same variation pattern. The Suntong coal mine, Taoyuan coal mine and Luling coal mine are located in the outer arc, middle arc and inner arc, respectively, and the $\mathrm{CBM}$ enrichment increases successively. The Suntong coal mine is located in the Tongting syncline with northwest-trending extensional fractures and normal faults, and the average CBM content of the minable coal seam is $3.04-8.33 \mathrm{~m}^{3} / \mathrm{t}$. The Taoyuan coal mine lies in the middle and features small local structures. The measured CBM content of the $\# 8_{2}$ coal seam is the largest $\left(9.70 \mathrm{~m}^{3} / \mathrm{t}\right)$. The Luling coal mine, located in the inner arc, has developed thrust faults and abundant CBM resources; its $\mathrm{CBM}$ content reaches up to $15 \mathrm{~m}^{3} / \mathrm{t}$. The geological reserve of $\mathrm{CBM}$ in the $\# 8$ coal seam alone is $1291.49 \mathrm{Mm}^{3}$, and the average resource abundance is $1.44 \times 10^{8} \mathrm{~m}^{3} / \mathrm{km}^{2}$.

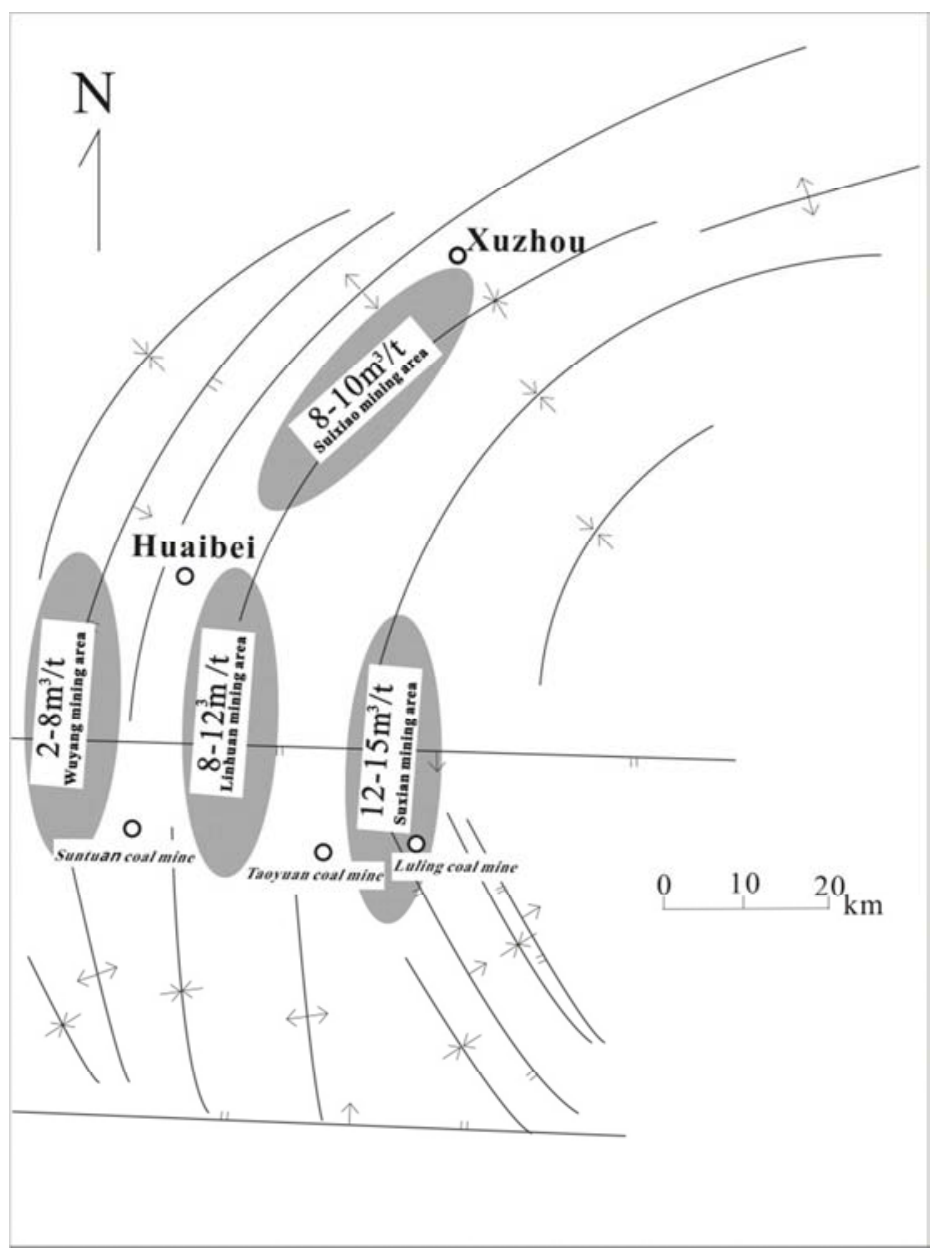

Figure 1. Schematic of CBM-bearing strata zonation of the Xusu arc structure control. 


\subsection{Division of CBM-Enriched Units in the No. 10 Mine of the Pingdingshan Coal Mining Group}

Mines of different tectonic scale and type also differ in influence property and scope. The main control structure was identified and CBM-bearing strata zonation was performed in the No. 10 Mine of the Pingdingshan Coal Mining Group. The main control structure of this mine controls the CBM enrichment law of the entire mining well. Some local structures only control local CBM enrichment (Figs. 2 and 3 ), and the CBM content can increase sharply within a radius of $15 \mathrm{~m}$. The Likou syncline is the main control structure of CBM enrichment in the entire Pingdingshan mining area and belongs to the wide and gentle syncline in the northwestsoutheast direction. The main control structures of the No. 10 Mine of the Pingdingshan Coal Mining Group are the thrust fault of the obsolete No. 11 Mine, developed on the south wing of the Likou syncline, and its recoil fault. Secondary fault propagation folds (Guozhuang anticline and No. 10 Mine syncline) located on the Likou syncline are formed by overthrust tectonics of the two faults, which determine the zoning of the CBM-bearing strata (Figs. 2 and 3). The No. 10 Mine of the Pingdingshan Coal Mining Group is divided into four units: shallow CBM-bearing strata, high-yield CBMbearing strata of the No. 10 Mine syncline, CBM-bearing strata of the Guozhuang syncline, and high-yield CBMbearing strata of the Likou syncline. Figure 3 shows the measured gushing amount of CBM for the recovery working faces $(22050,22060,17111,17131,22190,17030,17010$, 20120 and 20170); the gushing amount of CBM differs for each unit and does not necessarily increase with the burial depth. The gushing amount of CBM on the recovery working faces in the four CBM-enriched units listed above is 1.59 $\mathrm{m}^{3} / \mathrm{t}, 16.87 \mathrm{~m}^{3} / \mathrm{t}, 4.20 \mathrm{~m}^{3} / \mathrm{t}$ and $15.73 \mathrm{~m}^{3} / \mathrm{t}$, respectively.

Shallow CBM-bearing strata are free from the influence of a main control structure and the CBM content is low. CBMbearing strata of the Guozhuang syncline, which is also low in CBM content, is influenced by the thrust fault of the obsolete No. 11 Mine and its recoil fault. The two wings are subjected to a traction force in the opposite direction by the hanging wall of the thrust fault. The core of the anticline shows extensional fractures and the strata are of the extensional type. CBM enrichment is low despite the large burial depth. Due to the influence of the Niuzhuang thrust fault on the high CBM enrichment region in the No. 10 Mine syncline, the hanging wall is stretched by the nappe, while the footwall is squeezed with stress concentration. The fracture surface of the footwall is covered by the hanging wall, which makes the escape of CBM easier. The Yisi mining area is located in the middle and deep position of the Likou syncline located in the footwall under the obsolete No. 11 Mine, and CBM resources are more abundant in the nonexploited block.

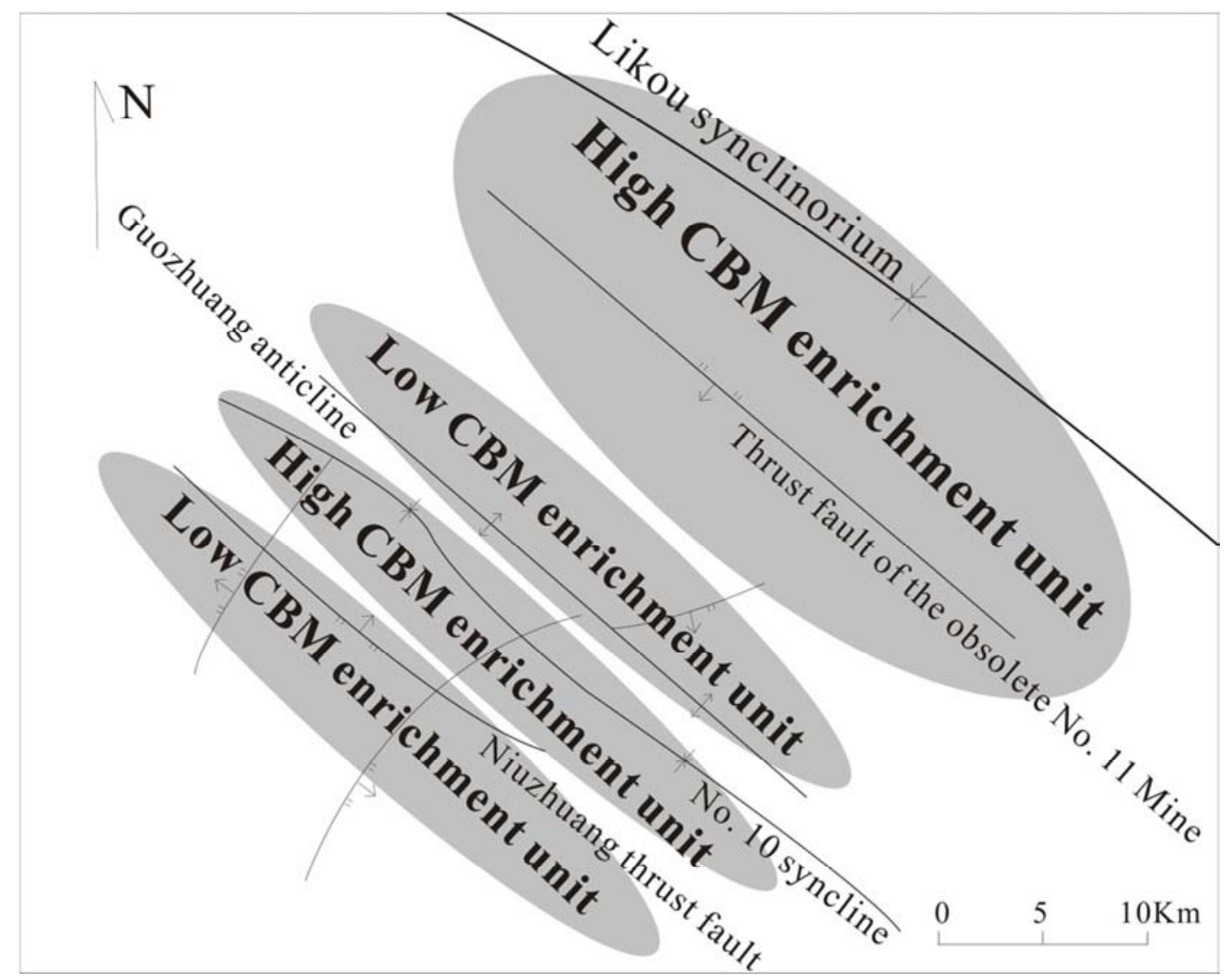

Figure 2. Plan view of the structures of Pingdingshan No. 10 Mine and CBM-bearing strata zonation. 


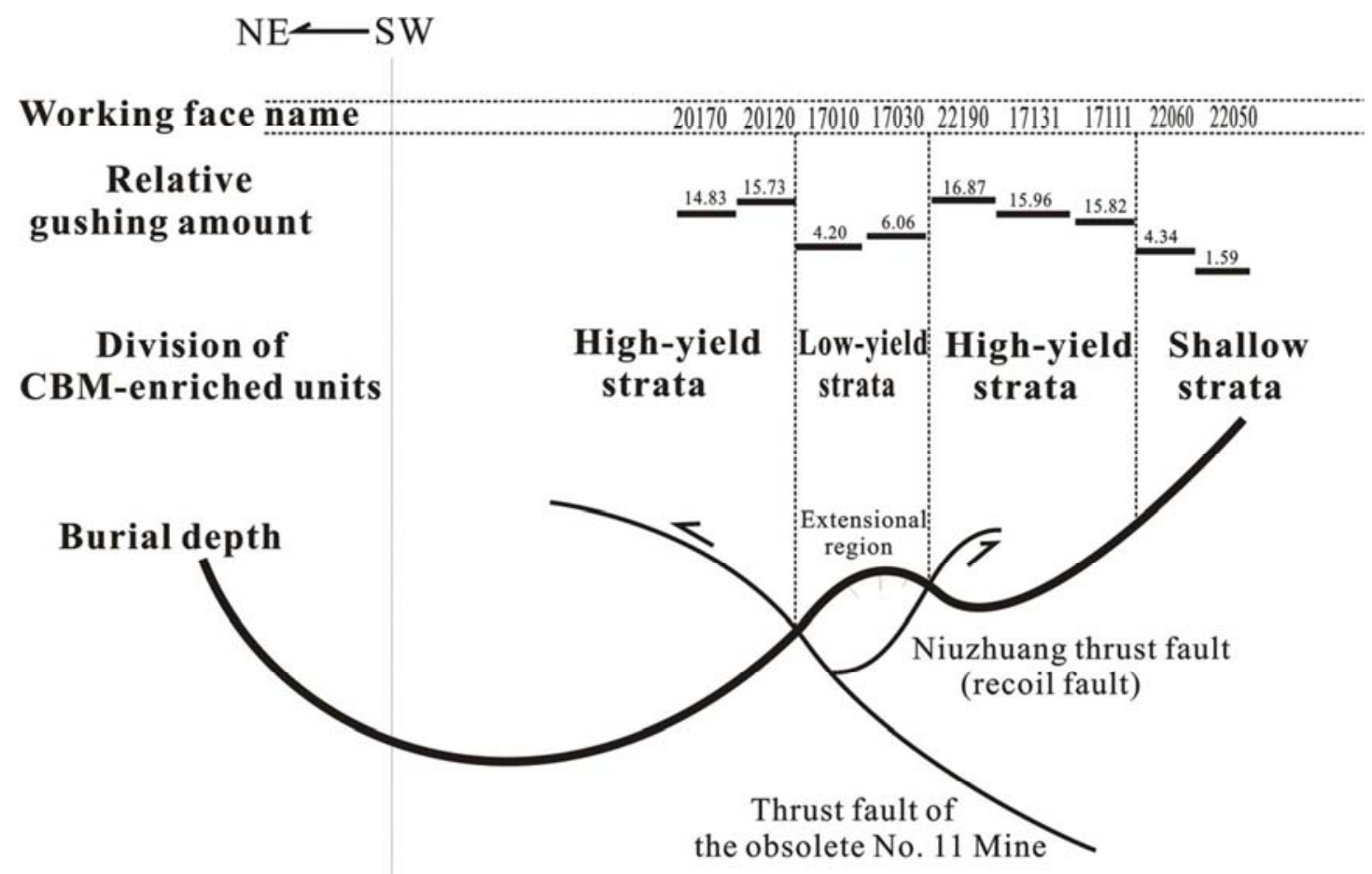

Figure 3. Plan view of the structures of Pingdingshan No. 10 Mine and CBM-bearing strata zonation.

\subsection{Division of CBM-Enriched Units in the \#II88 Mining Area in the Luling Coal Mine}

The \#II88 mining area in Luling coal mine displays features typical of the CBM-enriched units controlled by tectonic factors. The \#II88 mining area is located in the west of the Luling coal mine. The elevation of the coal seam floor ranges from $-375 \mathrm{~m}$ to $-590 \mathrm{~mm}$, and the surface elevation is $+24.0 \mathrm{~m}$ with an area of $644200 \mathrm{~m}^{2}$. The dip angle of the coal seam in the \#II88 mining area ranges from $10^{\circ}$ to $28^{\circ}$, with an average of $16^{\circ}$. The geological structures are quite complex, and there are 5 faults with an elevation drop greater than $20 \mathrm{~m}$. The CBM-bearing strata mainly strike NE and $\mathrm{NW}$, and small fractures have developed in this region. The $\mathrm{F}_{14}$ fault is the main control structure; located in the middle of the mining area, it controls the division of CBM-enriched units in the mining area.

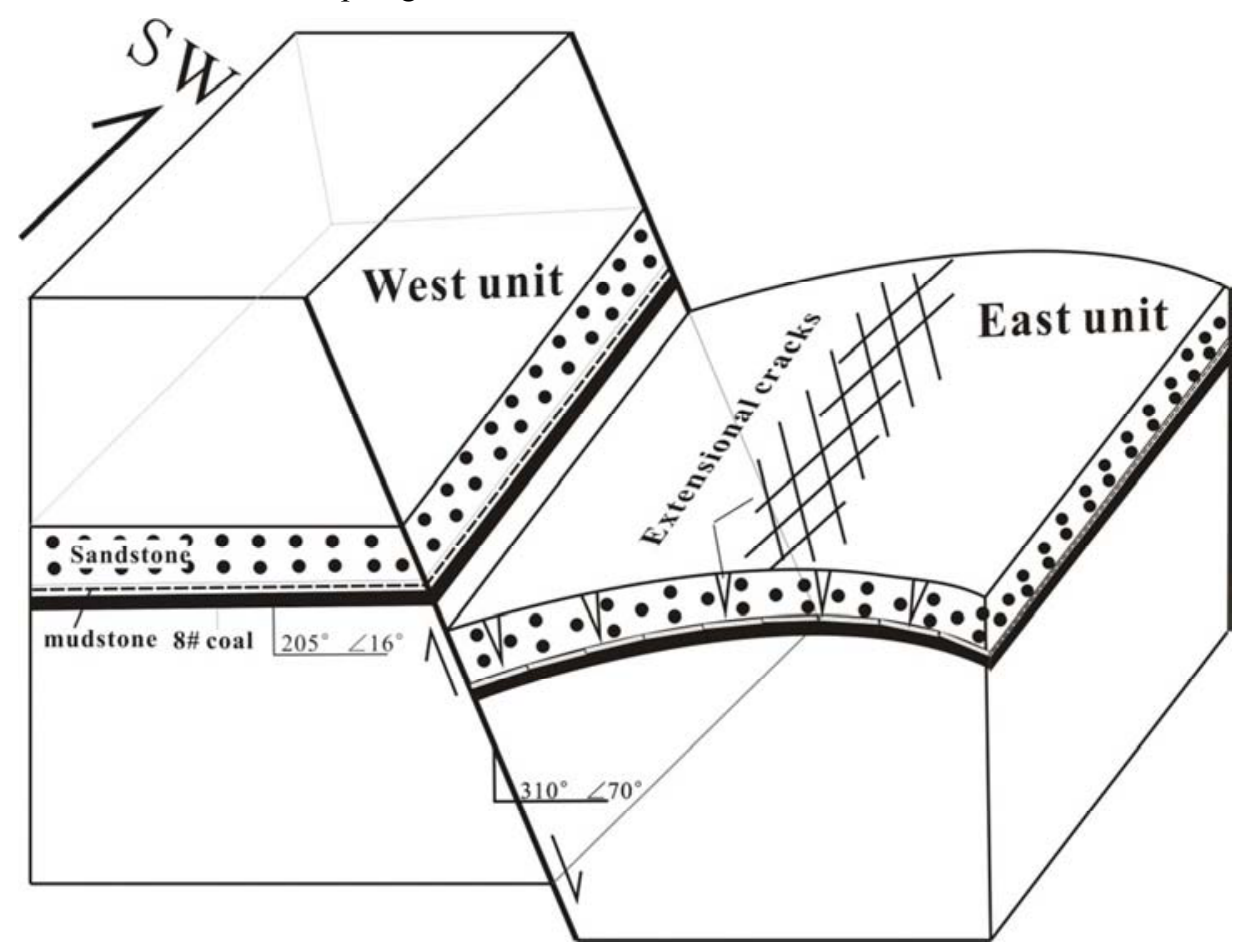

Figure 4. Kinetic model of CBM occurrence under $F_{14}$ fault control. 


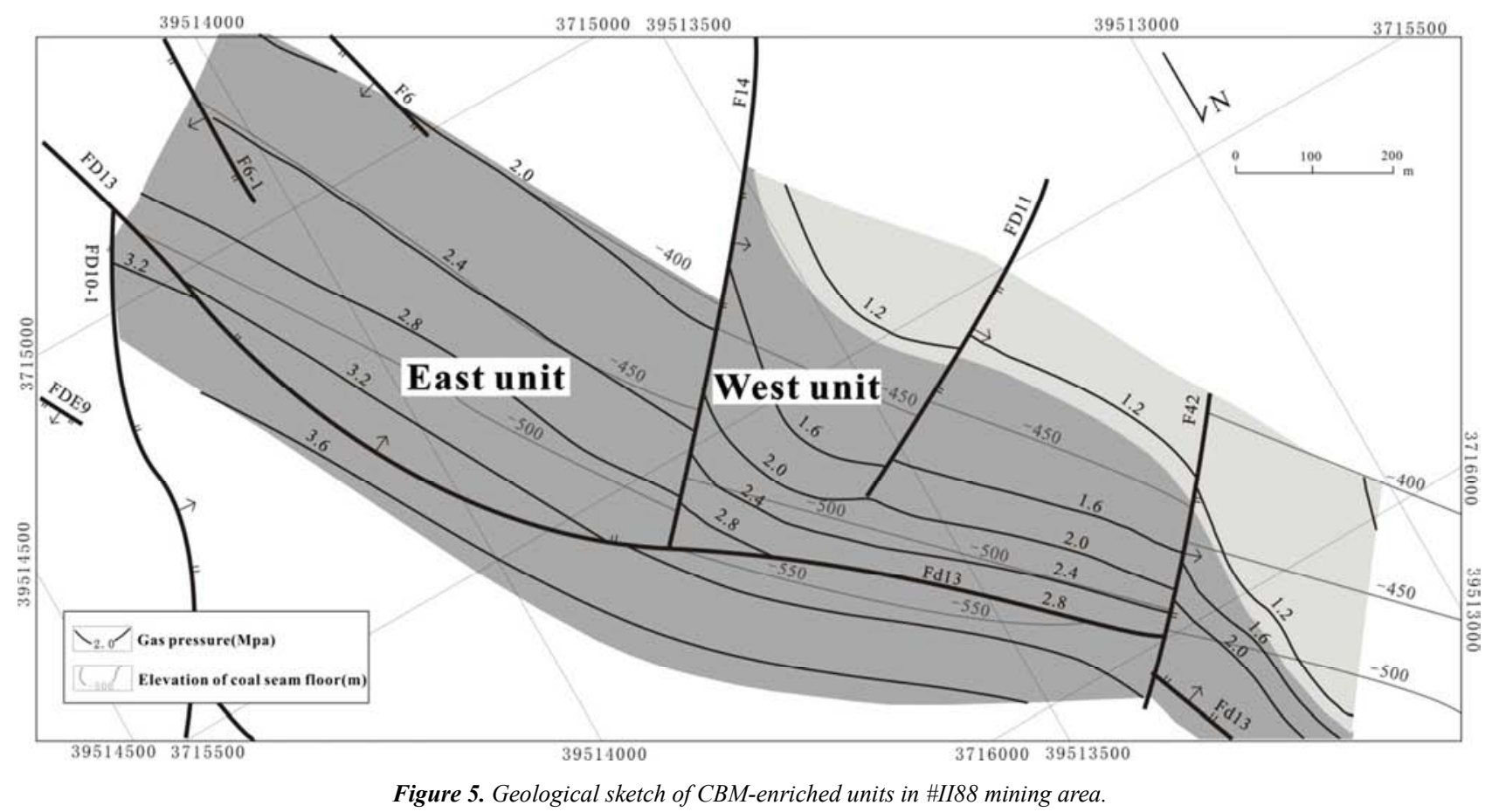

The $\mathrm{F}_{14}$ fault is the normal fault trending $\mathrm{NW}$ with a strike of $\mathrm{N} 40^{\circ} \mathrm{E}$, a dip angle of $60^{\circ}-75^{\circ}$, an elevation drop of $20-40$ $\mathrm{m}$ and a length above $1600 \mathrm{~m}$. This fault presents as a fractured zone with a width of $2-10 \mathrm{~m}$ upon revealing the rock roadway. Tectonic movement has altered the general law that the CBM content and pressure increase with lower elevation on two sides of the fault. The east CBM-enriched unit corresponds to the footwall of the $F_{14}$ fault, and its elevation is higher, but the gas pressure is also high; its CBM content and the gushing amount of CBM are large. The west CBM-enriched unit corresponds to the hanging wall of the $\mathrm{F}_{14}$ fault; its elevation is lower, but the gas pressure is lower than that of the east CBM-enriched unit. The reason for the deviation from the general law in the $\mathrm{F}_{14}$ fault is considered to be related to the damage of the coal seam roof in the hanging wall of the normal $\mathrm{F}_{14}$ fault by extensional movement. Although the elevation of the hanging wall of the fault decreases and the burial depth increases, the thin mudstone in the highstand systems tract overlying the \#8 coal seam is thinned or ruptured by the extensional movement of the hanging wall. Extensional cracks are produced as the sandstone layer forms the gentle rollover anticline. The top plate is damaged and some gas escapes. The footwall of the $\mathrm{F}_{14}$ fault has a larger elevation, but the mudstone on top of the \#8 coal seam at the footwall is not damaged during fault extension. The fracture surface of the coal seam may be sealed because of fault twisting and movement of the mudstone layer in the hanging wall, which creates favorable conditions for the preservation and enrichment of CBM (Figure 4). Moreover, the footwall of the $\mathrm{FD}_{13}$ fault has a larger burial depth and lies deep in the Sudong anticline with high CBM pressure. Based on the measured CBM pressure and content, $\mathrm{CBM}$ pressure gradient models were built for the east and west CBM-enriched units. The formula for predicting the $\mathrm{CBM}$ pressure in the east $\mathrm{CBM}$-enriched unit is $y=-0.0095 x-1.8028$, and the CBM pressure gradient is 0.95 $\mathrm{MPa} / 100 \mathrm{~m}$. For the west CBM-enriched unit, the formula for predicting the CBM pressure is $y=-0.0062 x-1.4286$, and the $\mathrm{CBM}$ pressure gradient is $0.62 \mathrm{MPa} / 100 \mathrm{~m}$. For the \#II88 mining area, the east and west $\mathrm{CBM}$-enriched units, divided by the $\mathrm{F}_{14}$ normal fault as the main control structure, differ significantly in CBM content and pressure (Figure 5).

\section{Burial and Hydrocarbon-Generation Histories}

Under constant ground temperature gradient and burial depth, as the coal grade increases, the CBM content increases as well. Under normal ground temperature gradient $\left(2.9^{\circ} \mathrm{C} / \mathrm{hm}\right)$ and normal reservoir pressure gradient $(0.98$ $\mathrm{MPa} / \mathrm{hm})$, as the coal grade increases, the saturated adsorption of the coal seam will increase [10-14]. The Licun coal mine of the Shanxi Lu'an Mining Group is a typical high-yield, high-efficiency and modernized mining well with high CBM enrichment. Moreover, abundant CBM parameter data are available for the Licun coal mine. The east and west wings of the No. 3 coal seam differ in the degree of metamorphism. Anthracite on the west wing has a high degree of metamorphism, while the meager coal on the east wing has a low degree of metamorphism. CBM content of the anthracite coal on the west wing ranges from 12 to 16 $\mathrm{m}^{3} / \mathrm{t}$. For every $100 \mathrm{~m}$ increase of burial depth, the CBM content gradient increases by $3.49 \mathrm{~m}^{3} / \mathrm{t}$ and the average adsorption constant $a$ is $37.13 \mathrm{~m}^{3} / \mathrm{t}$. The CBM content in the meager coal on the east wing ranges from 9 to $11 \mathrm{~m}^{3} / \mathrm{t}$. For every $100 \mathrm{~m}$ increase of burial depth, the CBM content gradient increases by $3.49 \mathrm{~m}^{3} / \mathrm{t}$, and the average adsorption constant is $31.13 \mathrm{~m}^{3} / \mathrm{t}$. 


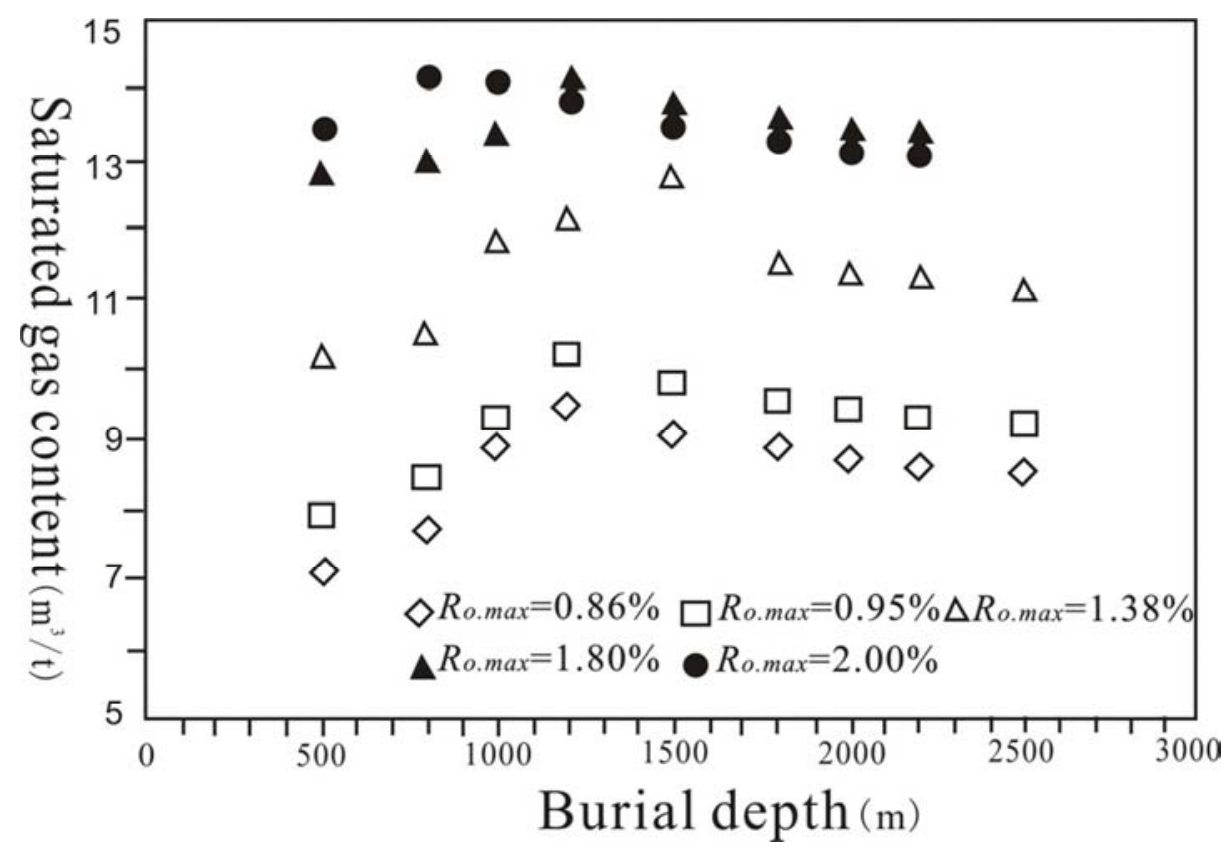

Figure 6. Relationship between saturated adsorption, coal grade and burial depth.

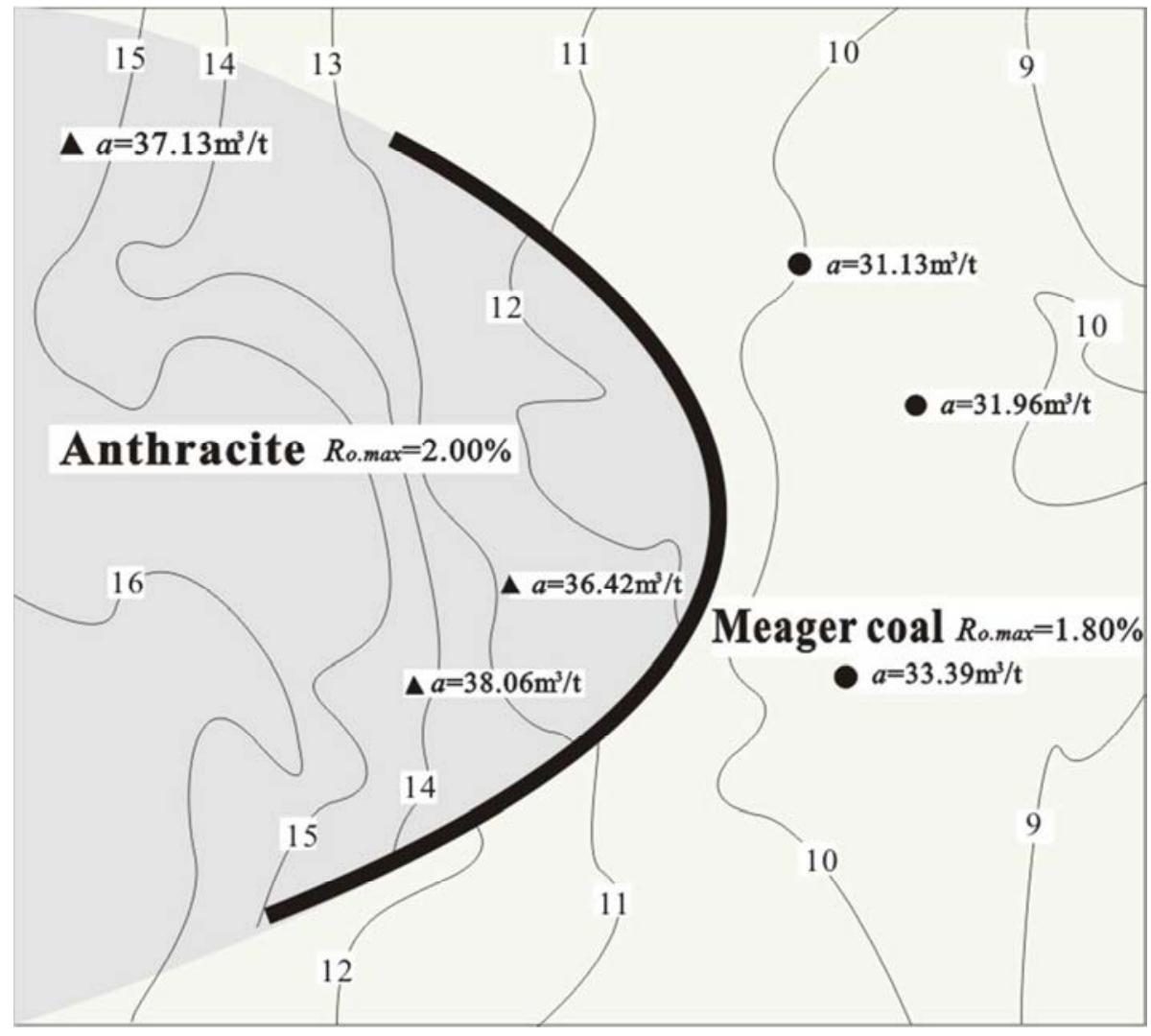

Figure 7. Sketch of division of CBM-enriched units in Licun coal mine.

\section{Conclusion}

The geological conditions of CBM in China are very complex, and the coal-bearing basins each have special features in some aspects. This leads to differences in the main controlling factors that are considered for the division of
CBM-enriched units. The history of CBM was tracked from formation to alteration, and the main controlling factors for the heterogeneity of CBM-enriched units were analyzed based on sedimentary sequences, tectonic movement and burial and hydrocarbon-generation histories. Division can be determined based on the following controlling factors: sedimentary environment or refined sedimentary sequences, 
tectonic movement and tectonic style, and burial history and degree of metamorphism. The division of CBM-enriched units for the orefield, mining wells and mining areas should be based on measured data (if available). The correlations of CBM content, gradient, coefficient of extraction difficulty and geological structure complexity vs. the main controlling factors provide key clues for the division. If there are no measured data available, the division can be done based on sedimentary sequences, tectonic movement, and burial and hydrocarbon-generation histories.

\section{Acknowledgements}

Chongqing science and technology innovation leader talent support program (CSTCKJCXLJRC14); National Key Research and Development Plan during the Thirteenth Fiveyear Plan Period (2016YFC0801404).

\section{References}

[1] Zhang QH, Li MJ, Wang QX et al. Gas Geology Methods Based on Large Data Thinking [J]. Coal Technology, 2015, 34(2): 75-77.

[2] Wang QX. Analysis and application of coal and gas outburst master control geologic body [J]. Safety in Coal Mines, 2015(46): 156-159.

[3] Wang QX. Analysis of typical main gas controlling structure [J]. Safety in Coal Mines, 2015, 46(11): 168-170.

[4] Wang QX. Gas control features of arcuate tectonic belts [J]. Journal of Henan Polytechnic University, 2015, 34(04): 451454.

[5] QIN Y, Xiong M, Yi TS et al. On Unattached Multiple Superposed Coalbed Methane System: in a Case of the Shuigonghe Syncline, Zhijin - Nayong Coalfield, Guizhou [J]. Geological Review, 2008, 54(1): 65-70.

[6] Zheng ZY, Qin, XH Fu, ZB et al. Multi-Layer Superposed Coalbed Methane System in Southern Qinshui Basin, Shanxi Province, China[J]. Journal of Earth Science. 2015(03).

[7] Shen J, Fu XH, Qin Y et al. Quantitative characterization of intensity of tectonic movement and its control on the coal and gas outburst in Panyi Coal Mine [J]. Safety in Coal Mines, 2010, 93-95.

[8] Dong GW, Zhang QH, Wang QX. Effect of sequence stratigraphy of the coal-bearing strata on goal and gas outburst in Shuicheng Mining Area [J]. Mining Safety and Environmental Protection, 2012(39): 17-19.

[9] Zhao MJ, Zhang SC, Zhao L et al. The thermal evolution history and oil and gas generation history of main source rocks in the Nanpanjiang Basin [J]. Petroleum Geology and Experiment, 2006(03): 117-119.
[10] Song Y, Liu HL, Liu SB et al. Coalbed Methane ReservoirForming Geology [M]. Beijing: Science Press, 2010.

[11] Wang HM, Zhu YM, Li W et al. Two major geological control factors of occurrence characteristics of CBM [J]. Journal of China Coal Society, 2011, 36(7): 1128-1134.

[12] Qin Y, Shen J, Wang BW et al. Accumulation effects and coupling relationship of deep coalbed methane [J]. Acta petrolei sinica, 2012(33): 48-54.

[13] ZHAO LJ, QIN Y, SHEN J. Adsorption Behavior and Abundance Predication Model of Deep Coalbed Methane[J]. Geological Journal of China Universities, 2012(18): 553-557.

[14] QIN Y, SONG QY, FU XH. Discussion on reliability for comining the coalbed gas and normal petroleum and natural gas: absorptive effect of deep coal reservoir under condition of balanced water [J]. Natural gas geoscience, 2005(16): 492498.

[15] Wang QX, Han WJ, Gao Y et al. Thinking and key technology of information mapping for coal-bed gas geology[J].Mining Safety and Environmental Protection, 2015,42(6): 93-95.

[16] Wang QX, Dong GW, Cui JF et al. Analysis of gas geology of \#III8 mining area in Luling Coal Mine [J]. Journal of Chengdu University of Technology, 2012, 39(01): 27-31.

\section{Biography}

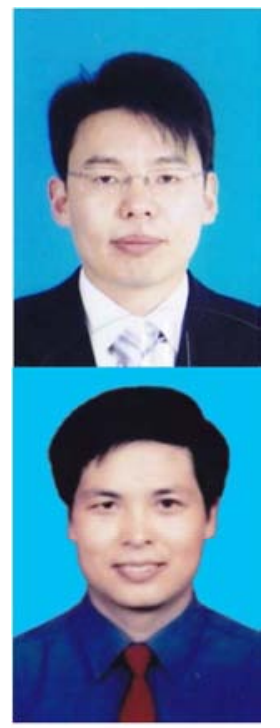

Zhang Qinghua (1979- ), male, born in Yuncheng, Shanxi Province; with a master's degree and now working as associate research fellow and director of Early Warning Research Institute; a member of China Coal Society and engaged in the research on the theory, technology and equipments of mine disaster early warning.

Zhao Xusheng (1969- ), male, born in Zhouzhi, Shanxi Province; now working as research professorship fellow and specialized in gas disaster prevention.

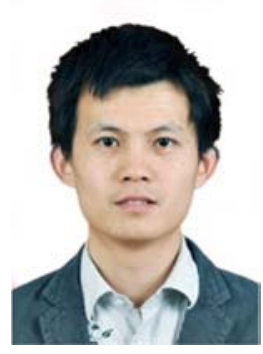

Wang Qixiang (1983- ), male, Manchu nationality, born in Dandong, Liaoning Province; now working as associate research fellow and specialized in structural geology and gas geology. 